\title{
PERFORMANCE ASSESSMENT OF ITALIAN SCHOOL HERITAGE ARCHITECTURE BY NON-DESTRUCTIVE INVESTIGATION
}

\author{
F. FATIGUSO, M. DE FINO \& A. SCIOTI \\ Department DICATECh, Polytechnic of Bari, Italy
}

\begin{abstract}
The restoration of Italian school heritage architecture is a crucial domain. This is mainly due to the general conditions of physical obsolescence and lack of maintenance, with relevant impacts at the technical, environmental, social, cultural and economic levels. In particular, the historic school buildings, dating back to the early 20th century, show specific issues, which should be carefully assessed. In detail, they are characterized by combined structural systems, with 'traditional' load-bearing masonry walls and foundations and 'modern' concrete and iron flooring solutions. They were conceived throughout a few decades, before the concrete framing system developed, following an empirical building practice, where any 'innovative' industrial materials used had not been thoroughly tested. Consequently, those buildings generally lack technical records on constructional techniques and technological solutions. Moreover, they have undergone very distinctive decay mechanisms and pathological patterns, related to the interaction between products and systems with incompatible or unpredictable performances. Finally, they require low invasive and compatible interventions, in order to preserve their unique structural and environmental balance, as well as their historical value. Based on some case studies of monumental school buildings in Bari, South Italy, this article discusses the identification methods for concrete and iron flooring systems in historic architecture of the early 20th century, in terms of constructional solutions and most recurring anomalies and pathologies. Furthermore, it focuses on non-destructive diagnostic techniques, as integrated with preliminary historic research, direct survey and comparative analysis with similar cases and technical records. The final goal is to develop some guidelines and tools - databases of building materials and techniques, charts of decay patterns and causes and tables for selection of onsite tests - as decision-making support throughout the pre-diagnosis. Those guidelines and tools should help identify the actual performances of such building systems and, thus, select the most effective, compatible and long-lasting maintenance solutions, in order to avoid local hazardous situations for vulnerable users.
\end{abstract}

Keywords: combined structural systems, non-destructive assessment, school heritage.

\section{INTRODUCTION}

The technical and scientific community has debated the assessment and retrofitting of the school built heritage for years at national and international levels. In particular, in Italy, as well as in most Mediterranean and Middle Eastern countries, the school buildings are mainly historic structures, with a great variety of technical and construction solutions. For that reason, the programmes under development for structural, energy and technological requalification should require specific methodological guidelines and operation practices for assessment and control of the overall performances, taking into account both the cultural and architectural values of the fabric and the requirements for safety, comfort and functionality for very vulnerable users [1-5].

Within the European framework, where the school buildings count for $17 \%$ of the built heritage and show general conditions of decay and poor performance [6], Italy is highly representative. According to recent statistics, there are approximately 52,000 school buildings in the national territory. Among them, 22\% were built before 1940 and $40 \%$ between 1940 and 1974. That scenario is reflected in the construction typologies. Besides buildings with stone 
(15\%), brick (14\%) and reinforced concrete structures (2\%), most schools show structural systems from the combination of the above-mentioned construction materials (67\%), for both vertical and horizontal components. Similarly, that scenario is reflected in the physical, functional, technological and normative obsolescence, greatly worsened by lack of maintenance. For instance, only $10 \%$ of the buildings have seismic protection measures, whereas $40 \%$ are located in high-risk seismic areas; only $1 \%$ were designed according to bioclimatic principles and more than $40 \%$ have never undergone energy-retrofitting works since their construction; about $30 \%$ call for urgent interventions for safety reasons [7-9].

Thus, the need to take action on such a wide and varied heritage comes up, with the combined purpose of conservation of cultural, historic and technical qualities, on the one hand, and mitigation of environmental, social and economic impacts, on the other hand.

Within that dichotomy, the diagnostic process, from assessment to diagnosis, can play a crucial role, in order to identify construction materials, building techniques and state of conservation, and, thus, recognize the values to preserve and assess the performances to improve, according to the well-established principles of minimum intervention, compatibility and reversibility [10-13].

\section{BACKGROUND}

Among the schools showing structural system from various construction materials, which is the most recurring construction typology, the historic buildings, dating back to the early 20th century, represent an interesting and challenging case, in the light of the above-mentioned issues, which should be carefully assessed and diagnosed. In detail, those buildings feature combined structural systems, with 'traditional' load-bearing masonry walls and foundations and 'modern' concrete and iron flooring solutions. They were conceived throughout a few decades, before the concrete framing system was developed, and they followed empirical building practices, where the 'new' industrial materials had not been thoroughly tested. Consequently, they generally lack technical records on materials, constructional techniques and technological solutions. Moreover, they have undergone very distinctive decay mechanisms and pathological patterns, mainly related to the interaction between products and systems with incompatible and/or unpredictable performances. In fact, they result from a very peculiar transition process, where the traditional culture of the Rule of Art merged with the experimental activity of the Industrial Revolution, which looked with enthusiasm to the employment of emerging artificial materials and techniques. Pre-modern construction flooring systems, stone and brick vaults and slabs with wooden beams and boards, were replaced with innovative and thus not thoroughly mature and reliable solutions: iron beams with stone or brick elements, concrete beams with cement or brick elements. It is worth mentioning that slabs with iron beams did not change the working scheme of construction, compared to slabs with wooden beams. For instance, the connections with the masonry walls were still performed by stone plates under the beam endings and by metal bars crossing the wall section. On the contrary, slabs with concrete beams locally modified the mechanical structure, due to their higher dead load, rigidity and capability to undergo differential settlements.

Nevertheless, they did not substantially change the global mechanical behaviour of the building system, so that their structural assessment is not dealt with herein. Differently, the present article is focused on the assessment of their physical obsolescence, which might cause local damage and risk for the users, due to falling parts in the bearing and not-bearing elements. In fact, besides the overall building structural vulnerability, many risks have recently come from detachment of plaster, concrete covers and infill members at the components level. 
For these components, the diagnostic process is focused on two aspects: (i) assessment of the building systems and sub-systems, for the documentation of construction practices and technical-technological solutions and the identification of the actual performances of materials and components; (ii) assessment of the state of conservation for the diagnosis of origin and magnitude of the pathological phenomena.

The above-mentioned targets are strictly related. Thus, they require a high level of data integration. The assessment of the building systems and sub-systems should concern the historic evolution from design/construction to in-use changes over time. Consequently, it should include the assessment of the state of conservation, which is due, beyond 'outer' agents, to 'inner' factors, such as design/construction and in-use faults, in terms of performance decay, vulnerability of interfaces between old and new systems, as well as mechanical, physical and chemical incompatibility. Furthermore, data acquisition relies on different methods and tools, from archivist and bibliographic research to geometrical survey, from visual inspection to experimental investigation. Since these methods and tools might provide partial information, due to limited availability of historic records, difficult accessibility of some parts of the building and/or operational constraints for on-site testing, data integration is required, not only because the targets are strictly related, but also because the tools to achieve those targets are complementary.

\section{METHODOLOGY}

In the light of the above-mentioned aspects, this article discusses the methodological process for the assessment of the flooring structural systems of the school built heritage, dating back to the early 20th century, with specific focus on the city of Bari, South Italy. It is worth mentioning that the case studies, 34 buildings completed before 1930, out of 130 over the territory, are highly representative of the great variety of technical and constructional solutions at the national scale. Thus, methods and tools, developed for the specific application, might easily cover a wider context (Fig. 1).

The methodological process (Fig. 2), comprising the well-established phases of knowledge, pre-diagnosis, diagnostics and diagnosis, is based on the integration of sources from the technical and scientific literature with records, analyses and measurements on the case studies. In detail, it addresses the technical-constructional assessment of the building components, the identification of the state of conservation and on-site investigation, towards the identification of the causes.

Specifically, for different building components - walls, slabs, staircases and balconies - the research has included several aspects, as follows:

- Technical-constructional assessment. This involves the comparative analysis of technical information from historic handbooks, journals and patents and from the case studies, in terms of archivist and bibliographic records, survey of geometry, mapping of construction materials and techniques. It results in inventory files within a general database.

- Identification of the state of conservation. This involves the study of atlases and models of pathologies and the analysis of the decay patterns, namely damp/cracking tables and surface alterations, in the representative buildings. It results in charts of pathologies and anomalies, related to the possible causes by correlation matrixes.

- On-site investigation. This involves the correlation of the most common diagnostic techniques with the technical-constructional assessment and the identification of the state of conservation, in order to support the reliable identification of the causes. It results in techniques/components and techniques/causes tables, as decision-making support tools for selection of most appropriate tests, given the investigation targets and conditions. 

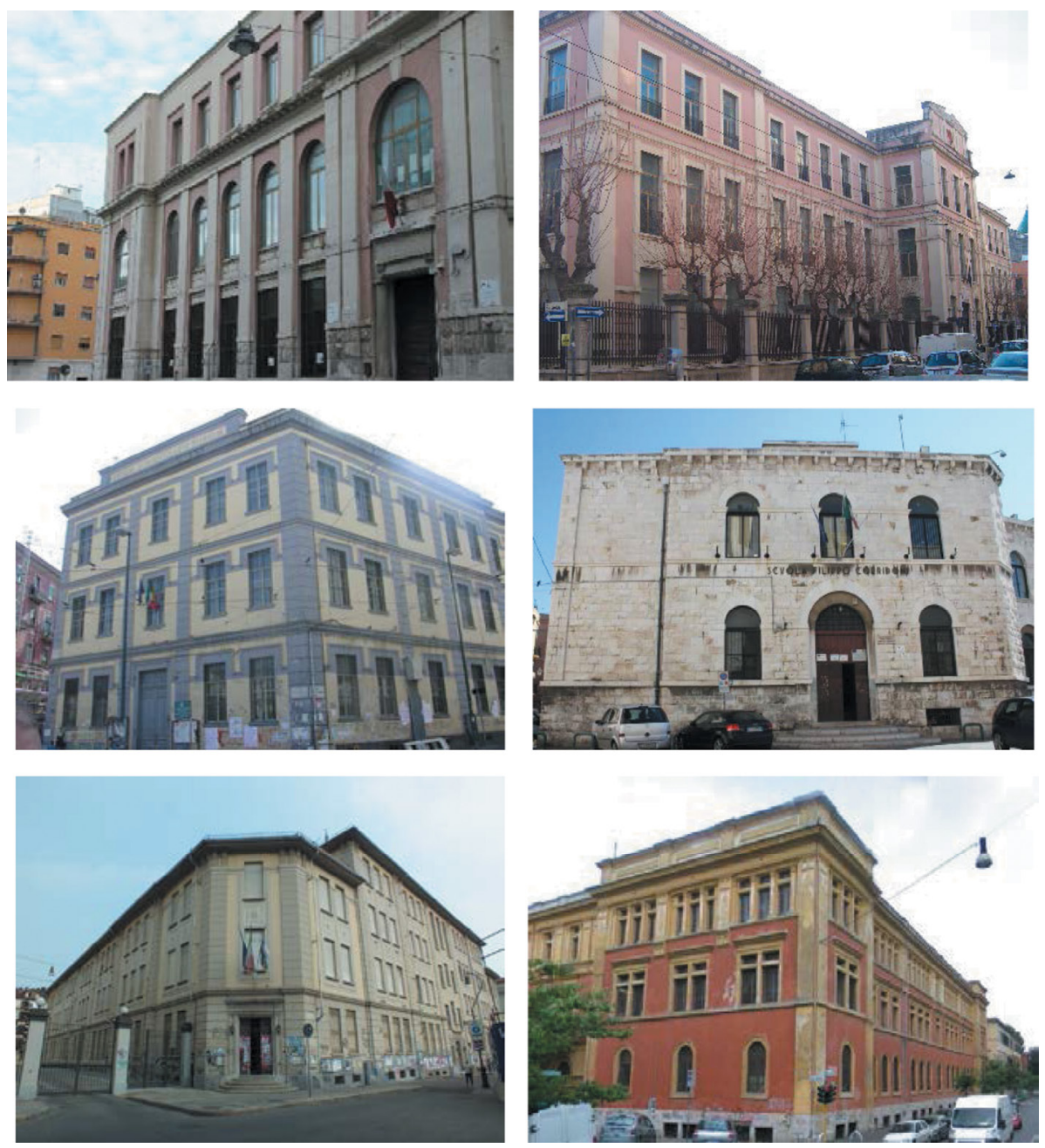

Figure 1: Representative case studies of the construction typology (clockwise from the top left: The schools Principessa di Piemonte, Bari; C. Del Prete, Bari; F. Corridoni, Bari; L. Miraglia, Naples; I. Calvino, Turin; E. Morante, Rome).

For the sake of brevity, the above-listed aspects are herein discussed for slabs, as highly illustrative of the overall topic, in terms of danger in the event of local failure.

\section{RESULTS}

\subsection{Technical-construction assessment}

As far as the technical-construction assessment is concerned, the technical information from historic handbooks, journals and patents was compared with the characteristics of the building components in the case studies. The comparison led to the classification of 'categories', related to the material of the primary load-bearing structure; 'types', related to the 


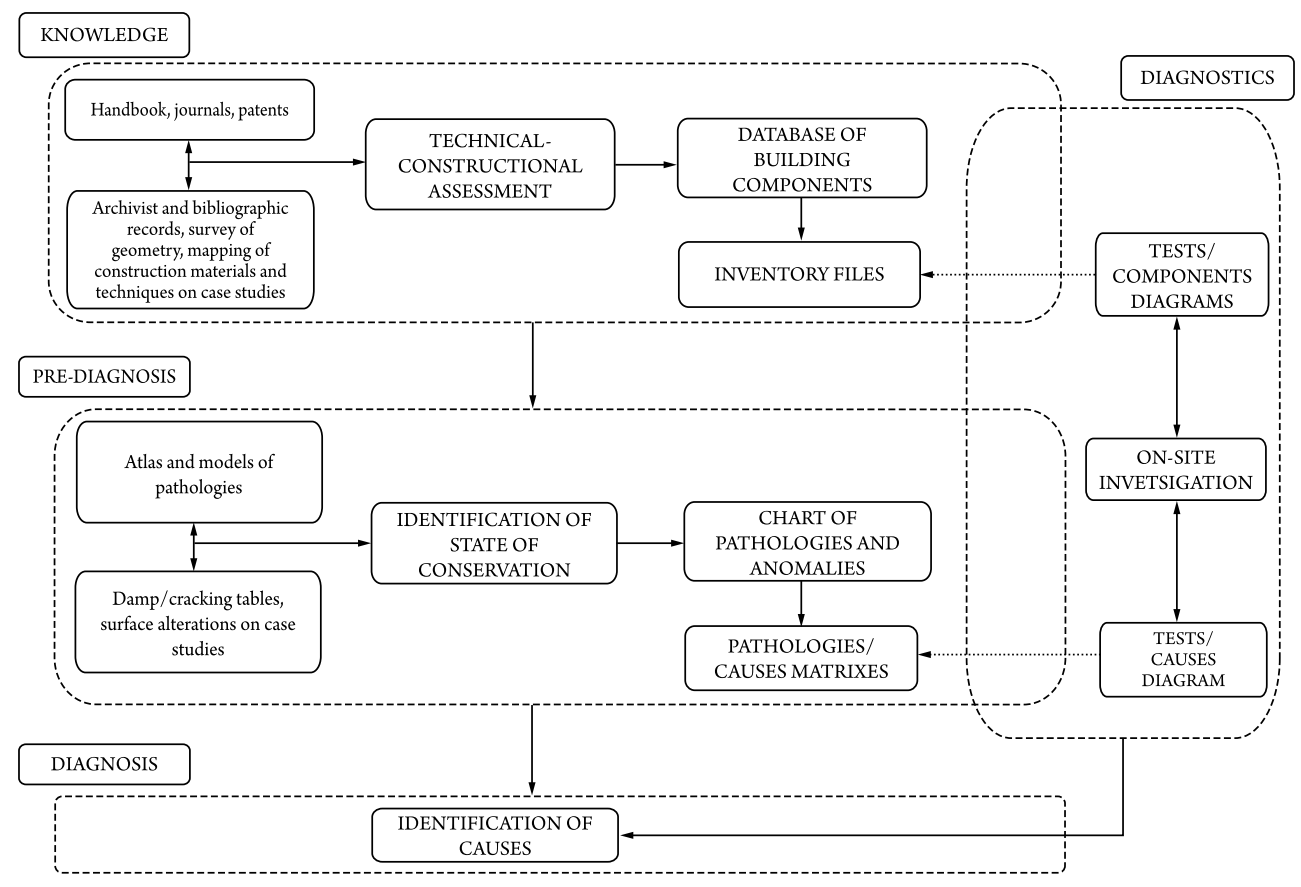

Figure 2: Methodology scheme.

material of the secondary non-load-bearing structure; and 'sub-types', related to the shape of the secondary non-load-bearing structure (Table 1).

In detail, from the traditional slab with timber beams and boards (A1), in the second half of the 19th century, the employment of iron elements started to take place [14], due to the development of the cast-iron market and the increasing costs of wooden products, which were in great demand for the railway industry. At the beginning, iron I-beams were still installed with secondary timber joists and boards (B1).

Later, the secondary timber elements were replaced with natural or artificial elements (B2), in order to reduce the fire risk of using wood and the mechanical and hygrometric

Table 1: Classification of the building component 'slab'.

\begin{tabular}{|c|c|c|c|c|c|}
\hline \multicolumn{2}{|c|}{ Categories } & \multicolumn{2}{|c|}{ Type } & \multicolumn{2}{|c|}{ Sub-type } \\
\hline A & Wood & 1 & Timber & & \\
\hline \multirow[t]{6}{*}{ B } & Iron & 1 & Timber & & \\
\hline & & & & $\mathrm{a}$ & Small vaults \\
\hline & & 2 & Natural or artificial elements & $\mathrm{b}$ & Hollow tiles \\
\hline & & & & $\mathrm{c}$ & Hollow Blocks \\
\hline & & 3 & Metal sheets & & \\
\hline & & 4 & Cement materials & & \\
\hline \multirow[t]{2}{*}{$\mathrm{C}$} & Concrete & 1 & Reinforced concrete & & \\
\hline & & 2 & Artificial elements & & \\
\hline
\end{tabular}



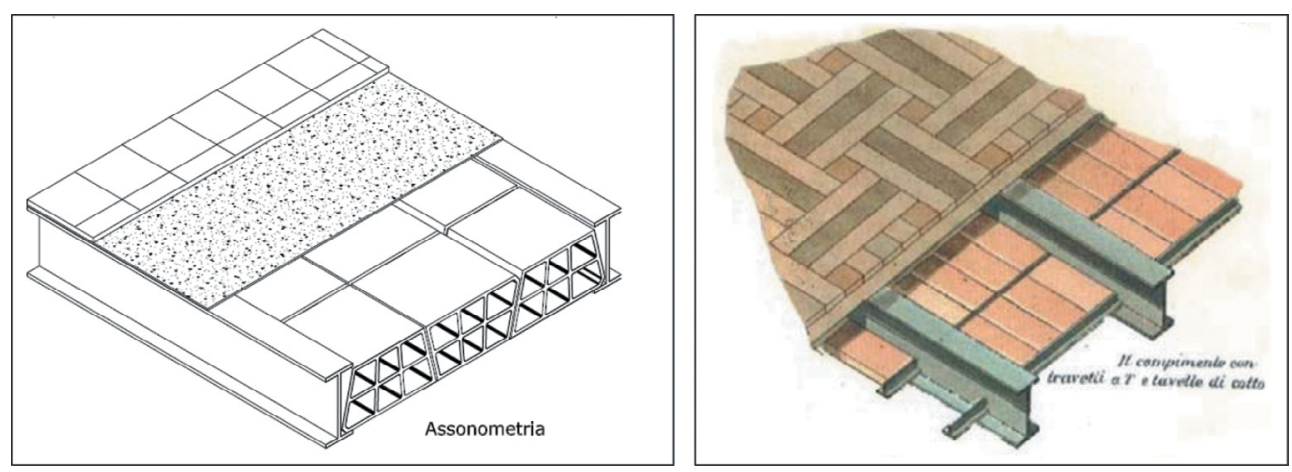

Figure 3: Record in the database from a historic handbook [16] - Slab B2b.
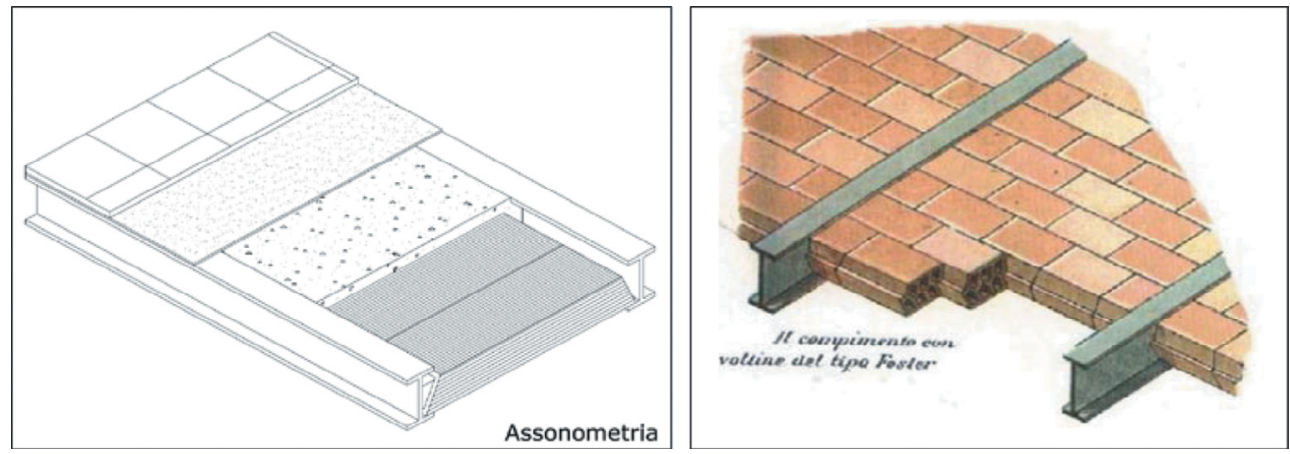

Figure 4: Record in the database from a historic handbook [16] - Slab B2c.

incompatibility between iron and wood [15]. At this stage, tuffo, brick and cement elements were used. The most common elements were bricks, in the shape of small vaults (B2a), hollow tiles (B2b) and hollow blocks (B2c), as in Figs 3-4 [16].

Especially for bricks, which could guarantee greater lightness, elasticity and resistance [17], several patents were registered. Among them, for instance, the slab by Ditta Frazzi was made of iron I-beams and hollow brick tiles, with a special 'brick piece' at the beam/tile connection to protect the thermal bridge at the intrados of the beams and a 'brick thin tile' at the intrados to create an air gap for thermal insulation (Fig. 5).

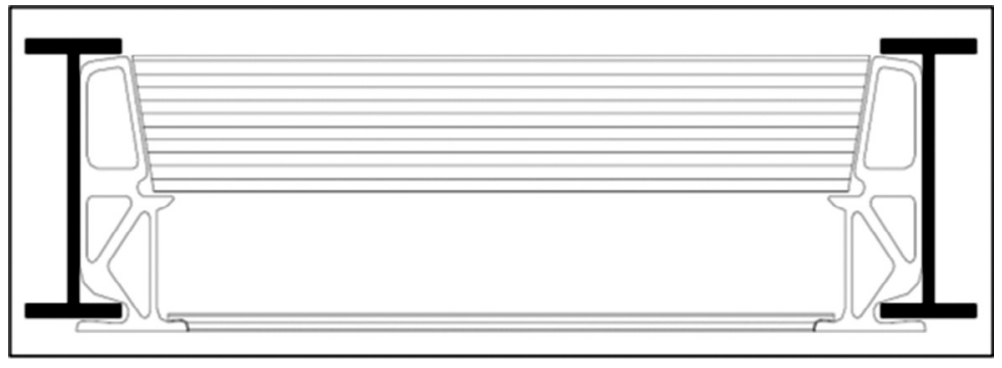

Figure 5: Scheme of the iron/brick slab manufactured by Ditta Frazzi. 
Along with iron/brick slabs, further solutions were introduced, such as iron/cement slabs (B3), where gypsum-cement mixtures were poured on a framework of iron cross beams [18] and, in a few cases, iron/steel sheet slabs (B4), in order to bear high loads.

Furthermore, the increasing employment of reinforced concrete structures initially included the introduction of continuous concrete slabs (C1), featuring high resistance, rigidity, durability, ease of installation, as well as heat and fire insulation [19]. Several patents were developed for that typology, for example, Coignet, Hennebique, Cottacin, Coularow and Walser-Gerard, which varied just in the arrangement of the reinforcement bars and brackets. Subsequently, the employment of reinforced concrete beams, in one or two directions, was exploited, with hollow brick blocks as secondary elements, with size and shape depending on the manufacturer (Fig. 6). For the last typology, the technical literature underlines the advantage of having special 'brick pieces' to protect the intrados of the concrete beams in order to avoid condensation of water vapour on the surfaces and facilitate the application of plaster [20].

Based on the data collection and management from different sources and records, which were briefly described above, for each category/type/sub-type solution, a specific inventory file has been developed (Fig. 7), in order to feed the general database, along with the similar files for all the building components - walls, staircases and balconies.

It is worth mentioning that all the theoretical models from handbooks, journals and patents were found in the practical case studies, which allows us to consider them as representative of the possible physical obsolescence, as detailed below.

\subsection{Identification of the state of conservation}

As far as the identification of the state of conservation is concerned, the survey of damp/ cracking tables and surface alterations of the building components in the case studies was

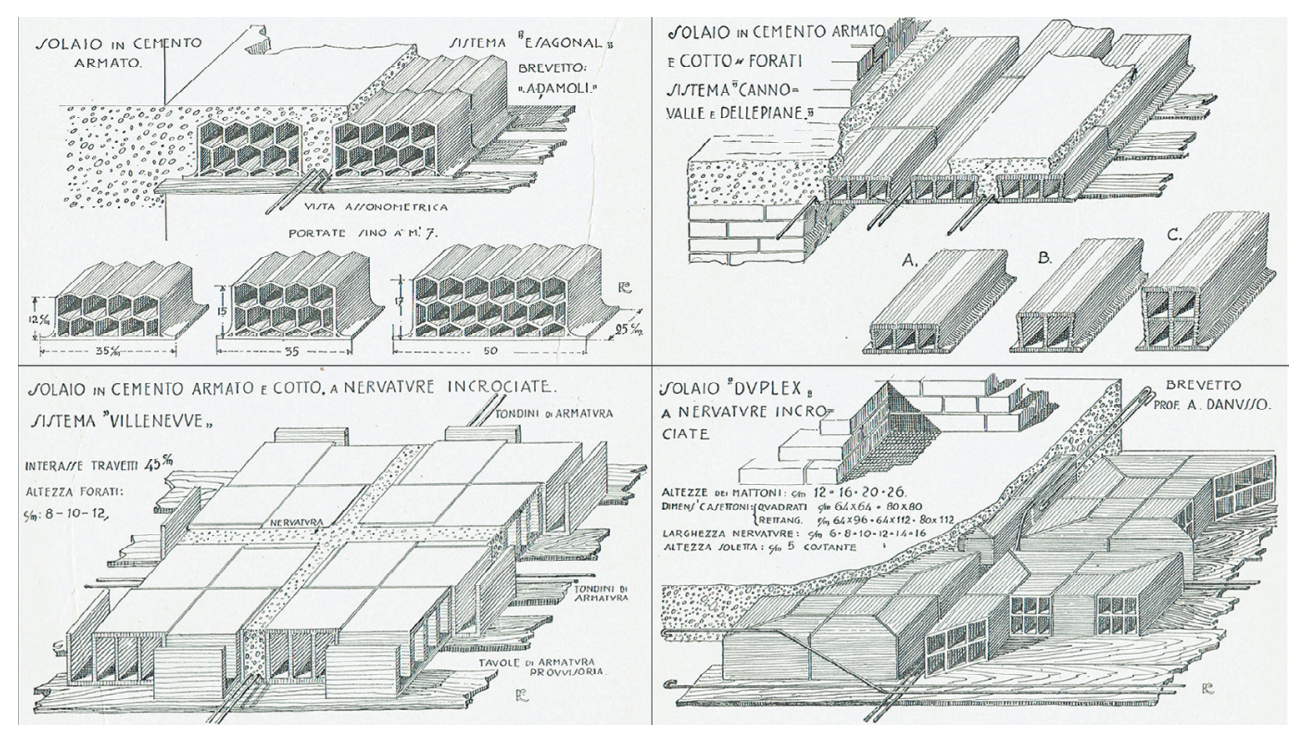

Figure 6: Record in the database from a historic handbook [20] - Slab C2. 


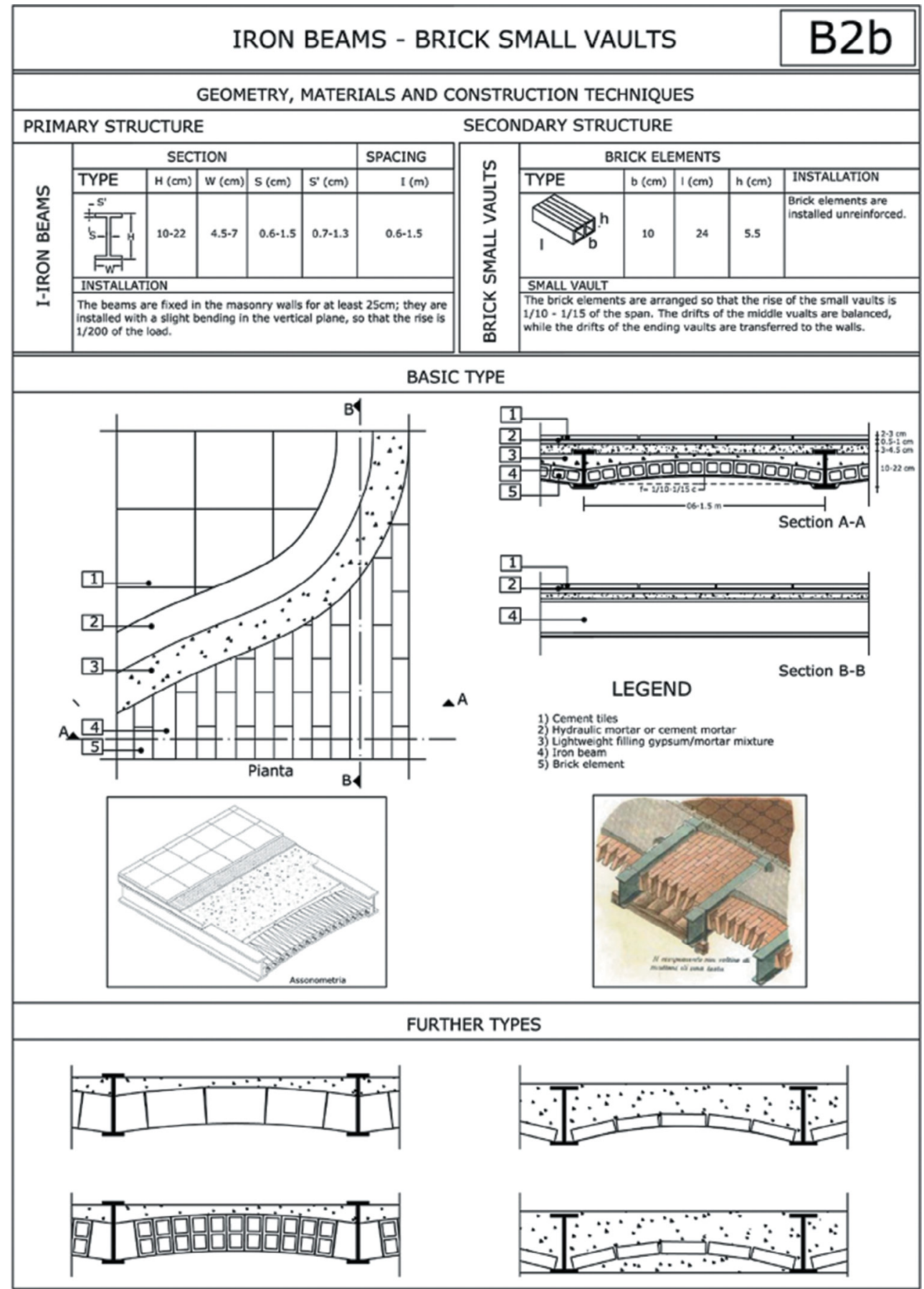

Figure 7: Inventory file - Slab B2a. 
related to atlases and models of pathologies, with specific attention towards the interfaces between different materials, in order to support the interpretation of the damage patterns due to mechanical, physical and chemical incompatibilities [21]. It is worth restating that the identification was carried out for both the primary and secondary structures, because, despite their different mechanical role, their obsolescence assessment is equally relevant to avoid local damage to the users, due to potential falling parts. In detail, concerning the slabs with iron beams, it was found that they generally show swelling and cracking of plaster at the interface between the primary and secondary structure, particularly in the case of natural/artificial blocks and cement materials. This damage pattern is due to the mechanical and physical incompatibility between different layers, the lack of protection of the iron beams at the intrados and the lack of a special 'brick piece' at the beam/brick interface. In some cases, aggressive environmental conditions have worsened the damage due to corrosion of the steel beams. Deformation of the iron beams often occurs, with subsequent cracking and detachment of the floor tiles at the extrados and, in the case of small brick vaults, fractures of the brick elements at the interface with the beams. Such damage is generally related to insufficiently resistant sections, considering the working loads and the slab span, and to mechanical-chemical-physical incompatibility between different layers. The mechanical incompatibility of the floor tiles at the extrados has accentuated the damage in some cases. All the slabs with iron beams also show several alterations of the primary structure, in terms of corrosion, with subsequent surface stains and deterioration at the intrados, as well as reduction of the resistant sections in the most severe cases. Whenever the secondary structure is made out of steel sheets, it has also undergone corrosion. Such damage is caused by aggressive environmental conditions, lack of maintenance and/or inadequate cleaning of the floor tiles at the extrados. Several damage patterns result from condensation of water vapour on the surfaces, particularly for iron beams and metal steel sheets, if they are not properly protected at the intrados or the maintenance has not been regular and effective. Furthermore, cracking all over the secondary structure, especially in the slabs with cement materials, results from chemical-physical incompatibility between different layers, over-deformability of the iron beams, inadequate manufacturing, installation and/or curing of the concrete and loads exceeding the designed levels. Similarly, concerning the slabs with reinforced concrete beams, surface stains and deterioration, as well as cracking and detachment of the plaster, appear due to mechanical-chemical-physical incompatibility between different layers and poor maintenance. Whenever the concrete covers are missing, crumbled or incoherent and the concrete elements have undergone fracture and delamination, again inadequate manufacturing, installation and/or curing of the concrete, loads exceeding the design, insufficient resistant sections and corrosion of the metal bars might happen. The same factors cause the fracture of brick elements in the secondary structure. The correlation matrix in Table 2 summarizes the most commonly recurring damage patterns and relative possible causes for iron/brick and concrete/brick slabs. Similarly, to the inventory files in the database for the technical-constructional assessment, this matrix, which was developed for all the building components (walls, staircases and balconies), is linked to charts of pathologies, as detected in the case studies and shown in Figs 8 and 9.

\subsection{On-site investigation}

As far as the on-site investigation is concerned, the research has focused on the selection criteria and application principles of the most common diagnostic techniques, as support tools 
Table 2: Correlation matrix between building components, damage pattern and pathology causes - Slabs B2 and C2.

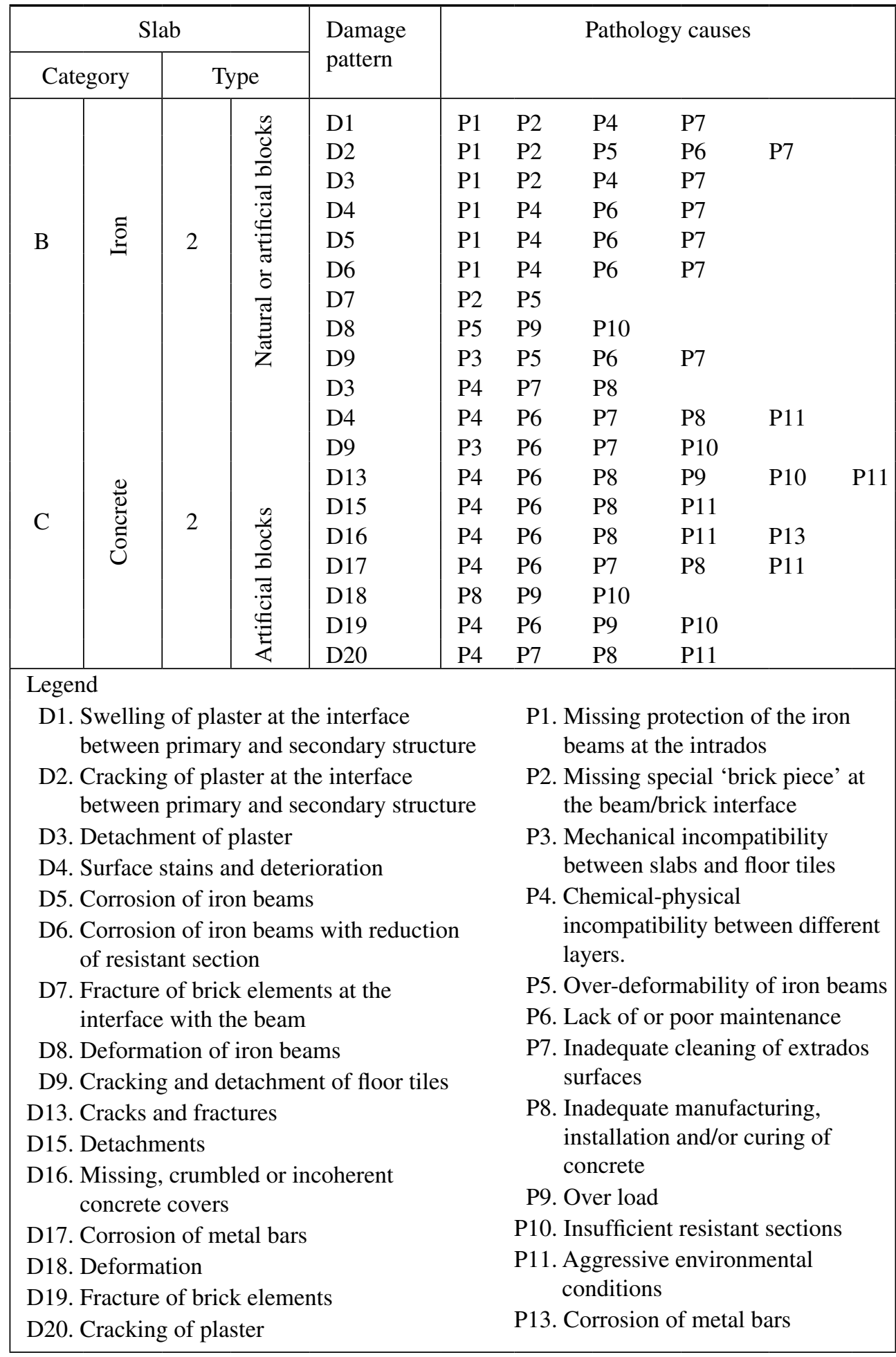



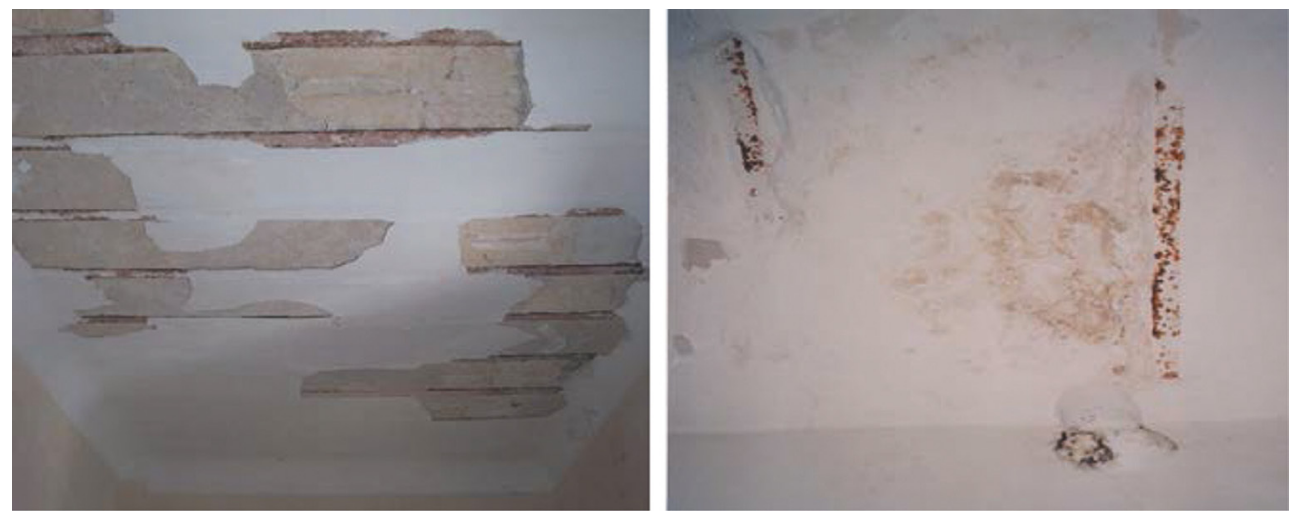

Figure 8: Record of the chart of pathologies (D3 and D4/5) - Slab B2.
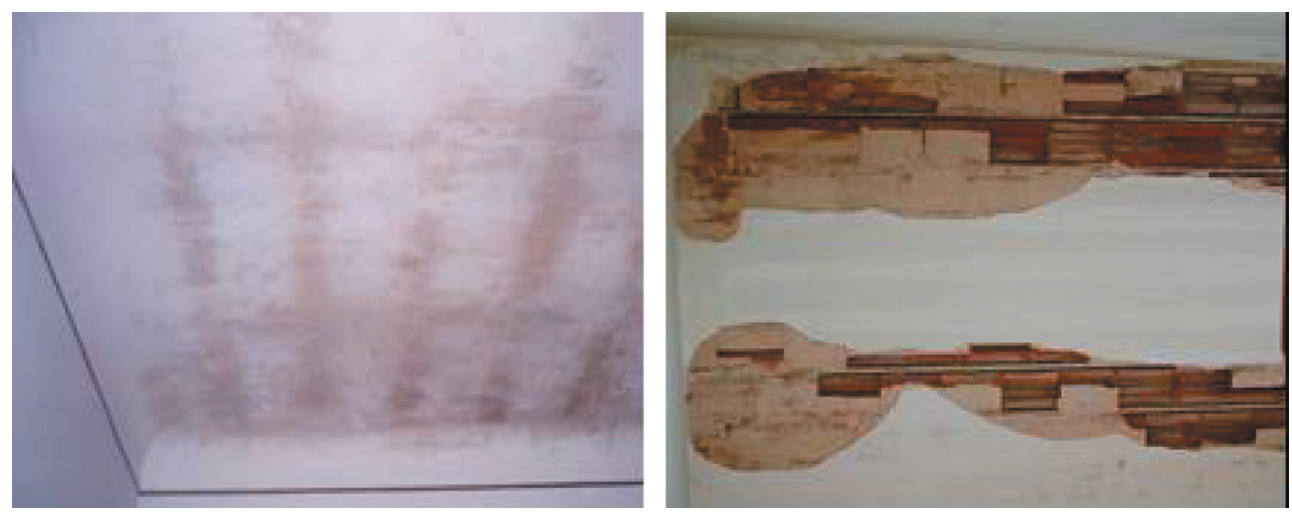

Figure 9: Record of the chart of pathologies (D3 and D7) - Slab C2.

within both the previous phases of technical-constructional assessment and identification of the state of conservation.

Concerning the correlation between on-site investigation and technical-constructional assessment, following the preliminary phase of direct survey, radar investigation of the extrados should provide the most complete information, particularly when the intrados is covered by false ceilings, which is quite common in school buildings. For the investigation of floor slabs, high-frequency antennas (1-2 GHz) are recommended to enable accurate signal resolution and two acquisition profiles, across the slab span in both longitudinal and transversal directions [22]. The expected results are the detection of different responses from the primary and the secondary structure, whenever different materials are featured in them, so that the geometry and morphology of the elements can be assessed. Consequently, the technique should be reliable for B2, B4 and C2. On the contrary, it might fail for B3 and C1. In the latter case, the low thickness of the sheets might make the measurements even more challenging.

In order to better explain the efficacy of radar scanning, Figs 10 and 11 show the outcome from a slab with iron beams and small brick vaults and a slab with concrete beams and hollow brick blocks, respectively. In the former case, wide reflections, in the shape of hyperbola, occur on top of the iron beams. Curved reflection profiles are visible, as well, corresponding to the brick small vaults. In the specific application, Fig. 10 also shows the presence of 


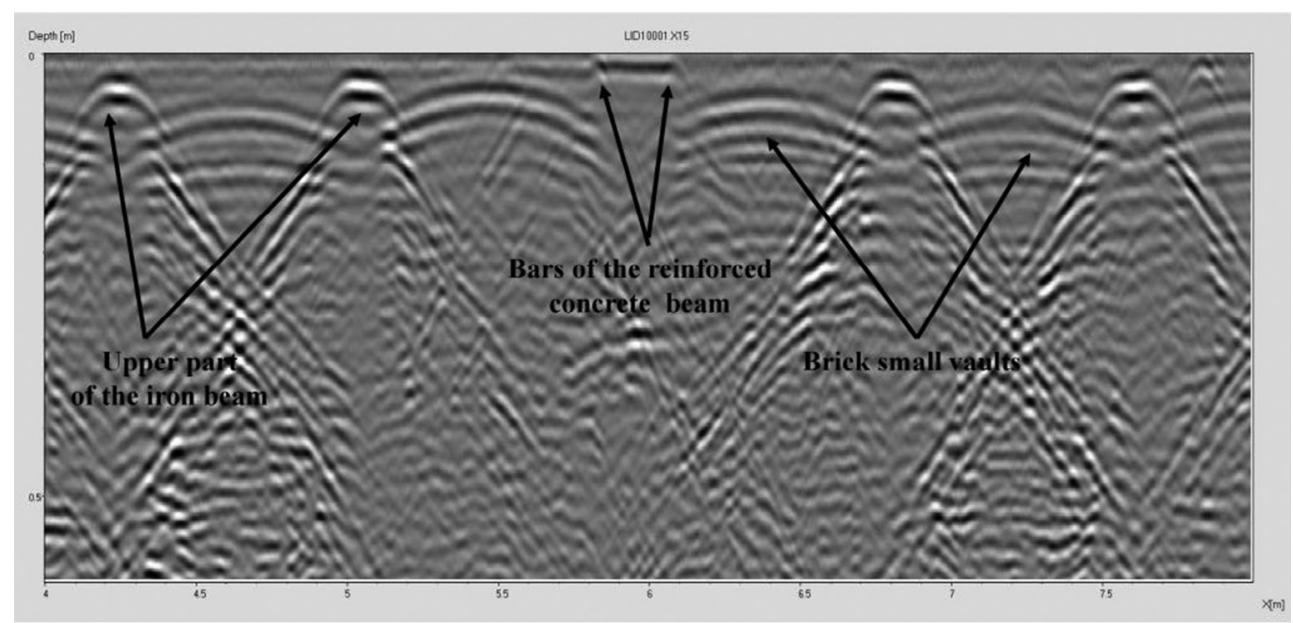

Figure 10: Record of the repertory of radar measurements - Slab B2a.

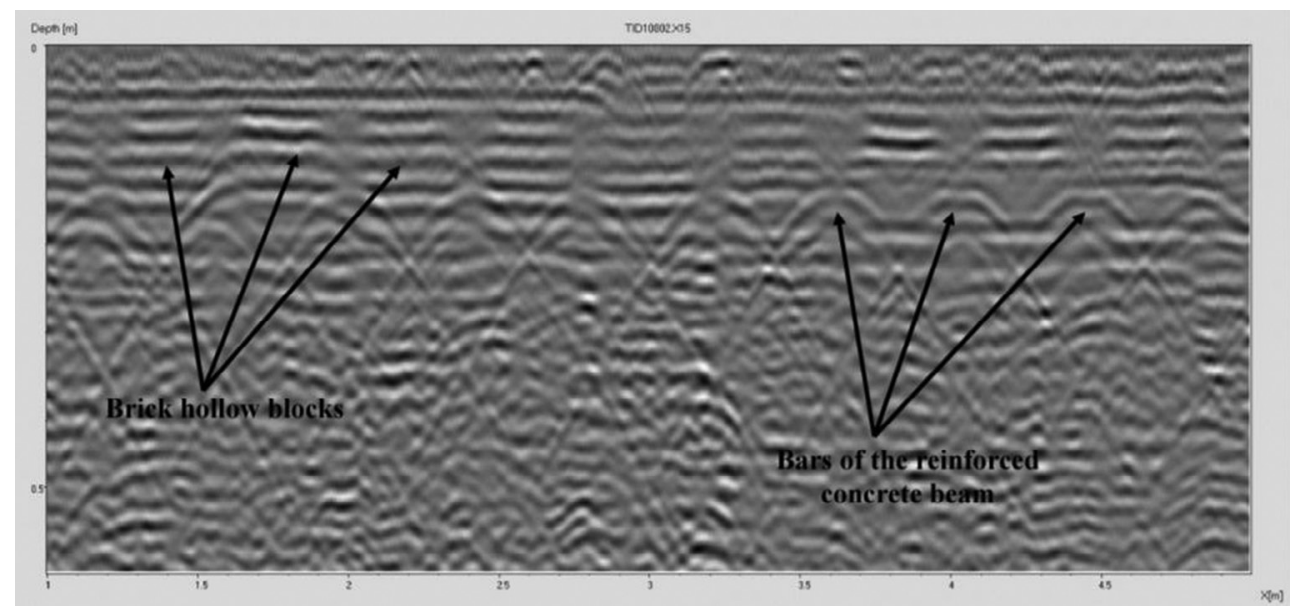

Figure 11: Record of the repertory of radar measurements - Slab C2.

a reinforced concrete beam whose upper reinforcement bars result in two small hyperbolas, just below the investigation surface and right in the middle of the displayed radargram. In the latter case, the radargram shows closer and smaller reflection hyperbola, reasonably due to the lower thickness of reinforcement bars in the concrete beams of the slab. Moreover, above the hyperbola, areas with low reflection/high transmission would correspond to the concrete beams themselves. Differently, small reflection planes, due to the holes in the brick blocks, characterize the contiguous areas.

The technical-construction assessment of the building components can also be achieved by thermography. The technique should be used to investigate the intrados, in passive or active mode, according to the surrounding environmental conditions [23]. The method relies on the detection of the emitted radiation in the infrared spectrum due to the surface temperature. Consequently, it enables the identification of the morphology of the primary and secondary structure at the intrados. Again, it can provide reliable data if the materials are different, in 

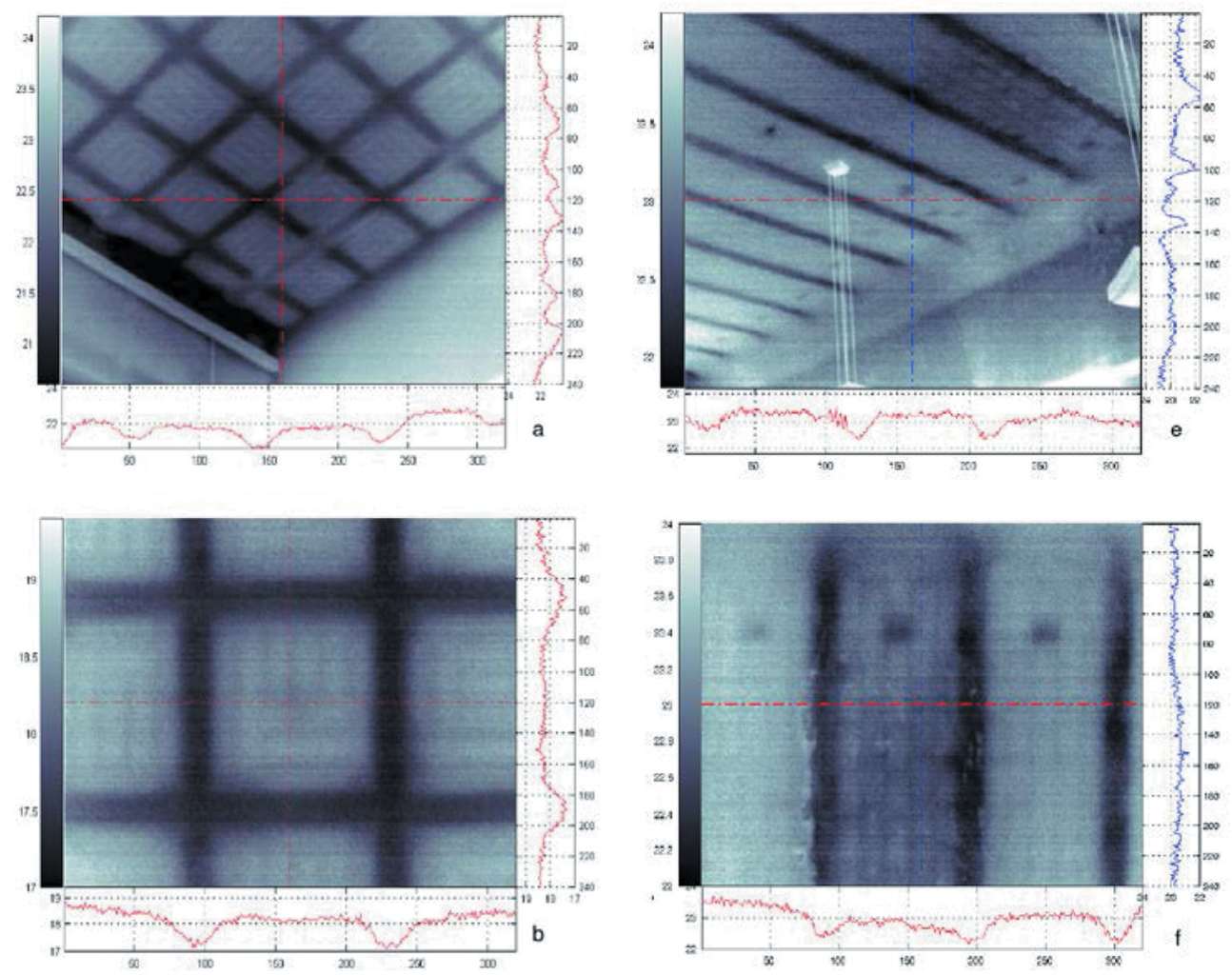

Figure 12: Record of the repertory of thermography measurements - Slabs C2 and B2a.

terms of thermal properties, such as B2, B4 and C2. On the contrary, similar materials, such as $\mathrm{B} 3$ and $\mathrm{C} 1$, would result in homogenous infrared behaviour.

In order to better explain the efficacy of the thermography, Fig. 12 shows some thermograms. Particularly, the thermograms where the picture plane is parallel to the intrados surface enabled to measure the dimensions of the elements, known the distance and the view factor of the thermocamera.

For all the floor slabs, and particularly for B3 and C1, which cannot be easily investigated by radar scanning or thermography, the magnetometric test might be quite useful. In fact, the technique can help assess the position, depth and thickness of the metal elements, based on the measurement of the magnetic field induced by the probe moving on the surface. A skilled operator should be able to distinguish the presence of iron beams and steel sheets, rather than reinforcement bars, taking into account the magnitude of the induced magnetic field.

Similarly, for all the slabs, video-endoscopy might be interesting. However, it is recommended for the validation on local and specific areas of the general results, previously achieved by extensive non-destructive tests.

Concerning the correlation between on-site investigation and identification of the state of conservation, the direct survey is crucial, especially when the damage patterns are visible on the intrados and extrados surfaces.

Again, radar scanning might support the assessment of the resistant sections, through detection of the height and/or width of the primary elements; the mechanical incongruence 
of the floor tiles, eventually resulting in reflection planes of discontinuity between floor and support; the characteristics of the concrete elements, by recognition of inner voids, fractures and cavities.

Thermography might be applied for all the cases where damage patterns result in thermal anomalies both directly - missing protection of the iron beams at the intrados, missing special 'brick piece' at the beam/block interface, corrosion of metallic elements - or indirectly chemical-physical incompatibility between different layers, lack of or poor maintenance and aggressive environmental conditions. Environmental conditions should also require monitoring of relevant microclimatic parameters, such as air temperature and relative humidity to assess the dew point.

Furthermore, the state of conservation of concrete structures should rely on specific techniques, such as ultrasound and rebound-hammer testing, combined in the SonReb method, in order to assess the compactness and resistance of the material, as well as measurements of carbonation depth and corrosion potential, in order to characterize the oxidation of metal bars. Similarly, on-site loading test might provide useful information on the deformability and resistance of the load-bearing structures.

Moreover, video-endoscopy inspection should be considered as complementary to the comprehensive non-destructive investigation. Finally, it should be underlined that all the above-mentioned techniques should be applied within integrated programmes, including limited destructive tests for validation of results and computation models with actual measured mechanical and physical characteristics.

According to the discussed issues, Tables 3 and 4 summarize the height of priority increasing from 0 to 10 - of different techniques for the elements and the pathologies, respectively. Those tables are related to repertories of experimental measurements, which include diagnostic data, such as those displayed in Figs 10-12.

\section{CONCLUSIONS}

This research has addressed the assessment of Italian school heritage architecture, with specific focus on historic buildings from the early 20th century, characterized by limited documentation, relevant historic value and intrinsic vulnerability. In particular, it involved the analysis of the flooring components by direct survey and experimental investigation of representative case studies, in terms of technical solutions and decay patterns, in correlation with historic handbooks, journals and patents, as well as atlases and models of pathologies.

The results include inventory files describing the construction-technical components of the most common flooring systems, charts of the most occurring pathologies with correlation to

Table 3: Tests/elements table

\begin{tabular}{rrrrrrr}
\hline & B1 & B2 & B3 & B4 & C1 & C2 \\
\hline I1 & 10 & 10 & 10 & 10 & 10 & 10 \\
I2 & 9 & 9 & 3 & 9 & 3 & 9 \\
I3 & 8 & 8 & 2 & 8 & 2 & 8 \\
I4 & 6 & 6 & 6 & 6 & 6 & 6 \\
I5 & 7 & 7 & 9 & 7 & 9 & 7 \\
\hline
\end{tabular}

Note: B1. Iron/wood; B2. Iron/brick; B3. Iron/s sheets; B4. Iron/concrete; C1. Concrete/concrete;

C2. Concrete/brick; I1. Direct survey; I2. Radar; I3. Thermography; I4. Video-endoscopy;

I5. Magnetometer testing. 
Table 4: Tests/pathologies table.

\begin{tabular}{rrrlllllllr}
\hline & P1 & P2 & P3 & P4 & P5 & P6 & P8 & P10 & P11 & P13 \\
\hline I1 & 10 & 8 & 6 & 6 & 8 & 6 & 6 & 6 & 2 & 10 \\
I2 & 0 & 0 & 7 & 0 & 0 & 0 & 7 & 9 & 0 & 0 \\
I3 & 10 & 10 & 0 & 5 & 0 & 5 & 0 & 0 & 5 & 10 \\
I4 & 0 & 0 & 0 & 0 & 0 & 0 & 9 & 9 & 0 & 9 \\
I5 & 5 & 0 & 0 & 0 & 0 & 0 & 0 & 3 & 0 & 3 \\
I6 & 0 & 0 & 0 & 0 & 0 & 0 & 8 & 0 & 0 & 0 \\
I7 & 0 & 0 & 0 & 0 & 0 & 0 & 0 & 0 & 0 & 10 \\
I8 & 0 & 0 & 6 & 0 & 0 & 0 & 6 & 10 & 0 & 0 \\
I9 & 0 & 0 & 0 & 0 & 0 & 0 & 0 & 0 & 10 & 0 \\
\hline
\end{tabular}

Note: I1 Direct survey; I2. Radar; I3. Thermography; I4. Video-endoscopy; I5. Magnetometer testing; I6. SonReb; I7. Carbonation/corrosion potential; I8. On-site loading test; I9. Microclimatic monitoring.

possible causes, as well as repertories of the most suitable testing and monitoring technologies with tables showing the suitability for the above-mentioned components and pathologies and some illustrative outputs for thermography and radar scanning.

The results have been used to compile a database that could be used as an information system to document case studies. Furthermore, they might be used as decision-making tools for technicians, enterprises and school administrators in similar cases and as methodological guidelines in other cases under different conditions. Finally, the variety of the aspects and methods involved has confirmed the need for an integrated diagnostic approach, including analysis of documental sources, application of on-site investigation tools and interpretation of correlated results. The final goal is the achievement of compatible and suitable interventions from the reliable assessment and control of the overall performances, taking into account both the cultural and architectural values of the fabric and the requirements for safety, comfort and functionality for very vulnerable users.

\section{REFERENCES}

[1] Tadeu, S., Rodrigues, C., Tadeu, A., Freire F.\& Simões N., Energy retrofit of historic buildings: Environmental assessment of cost-optimal solutions. Journal of Building Engineering, 4, pp. 167-176, 2015. DOI: 10.1016/j.jobe.2015.09.009

[2] de Santoli, L., Fraticelli, F., Fornari, F. \& Calice C., Energy performance assessment and a retrofit strategies in public school buildings in Rome. Energy and Buildings, 68-A, pp. 196-202, 2014. DOI: 10.1016/j.enbuild.2013.08.028

[3] Lourenço, P., Pinheiro, M.D. \& Heitor, T., From indicators to strategies: Key performance strategies for sustainable energy use in Portuguese school buildings. Energy and Buildings, 85, pp. 212-224, 2014. DOI: 10.1016/j.enbuild.2014.09.025

[4] Yilmaz, S., Tama, Y.S. \& Bilgin, H., Seismic performance evaluation of unreinforced masonry school buildings in Turkey. Journal of Vibration and Control, 19(16), pp. 2421-2433, 2013. DOI: 10.1177/1077546312453190

[5] Azarbakht, A., Seismic rehabilitation of traditional unreinforced masonry buildings in Iran. Proceedings of the COMPDYN 2011 - III ECCOMAS Thematic Conference on Computational Methods in Structural Dynamics and Earthquake Engineering, Island of Corfu, Greece, 2011. 
[6] Trachte, S. \& De Herde, A., Sustainable Refurbishment of School Buildings, IEA SHC publication, University of Louvain la Neuve, Belgium, 2015.

[7] Rapporto Cresme RI.U.SO 03 - 2014 (in Italian).

[8] Audizione dell'Ance sulla situazione dell'edilizia scolastica in Italia - 2013 (in Italian).

[9] XII Rapporto di Legambiente sulla qualità dell'edilizia scolastica, delle strutture e dei servizi - 2011 (in Italian).

[10] de Freitas, V.P., A State-of-the-Art Report on Building Pathology, CIB W86 Building Pathology. Vol. 393, Oporto, Portugal, 2013.

[11] Rogerio-Candelera, M.A., Lazzari, M. \& Cano, E., Science and Technology for the Conservation of Cultural Heritage, CRC Press Book: Boca Raton, Florida, 2013.

[12] Bosiljkov, V., Uranjek, M., Žarnić, R. \& Bokan-Bosiljkov, V., An integrated diagnostic approach for the assessment of historic masonry structures. Journal of Cultural Heritage, 11(3), pp. 239-249, 2010. DOI: 10.1016/j.culher.2009.11.007

[13] Anzani, A., Binda, L., Carpinteri, A., Invernizzi, S. \& Lacidogna, G., A multilevel approach for the damage assessment of historic masonry towers. Journal of Cultural Heritage, 11(4), 2010. DOI: 10.1016/j.culher.2009.11.008

[14] Curioni, G., L'arte di fabbricare, Tipografia A.F.: Negro, Torino, 1873.

[15] Breymann, G.A., Trattato generale di costruzioni civili, Vallardi: Milano, 1895-1903.

[16] Misuraca, G. \& Boldi, M.A., L'arte moderna del fabbricare: Trattato pratico ad uso degli ingegneri, costruttori, capimastri e studenti, Vallardi: Milano, 1916.

[17] Donghi, D., Manuale dell'architetto, UTET: Torino, 1906.

[18] Cantalupi, A., Istituzioni pratiche elementari sull'arte di costruire le fabbriche civili, D. Salvi \& C.: Milano, 1862.

[19] Levi, C., Trattato teorico-pratico di costruzioni civili, rurali, stradali, idrauliche (Vol. I), Hoepli: Milano, 1907-1911.

[20] Formenti, C., La pratica del fabbricare, Hoepli: Milano, 1933.

[21] Offenstein, F., Compatibilità dei materiali, UTET: Torino, 1995.

[22] De Fino, M., Scioti A. \& Fatiguso, F., Assessment of historic buildings by radar techniques, Structural Survey, 34(1), pp. 73-94, 2016. DOI: 10.1108/SS-07-2015-0035

[23] Amatulli, C., De Fino, M., De Tommasi, G., Fatigusom F. \& Stefanizzi, P., A protocol for active IR thermography to assess durability of building components. Proceedings of the 12th International Conference on Durability of Building Materials and Components, 12-15 April 2011, Porto, Portugal. 